\title{
AJARAN ETIKA HINDU DALAM CERITA SANTI PARWA
}

\author{
Oleh \\ Ni Made Sukerni \\ Dosen Pendidikan Agama IHDN Denpasar
}

\begin{abstract}
ABSTRAK
Teks-teks Itihasa saat ini sedang digandrungi masyarakat, khususnya umat Hindu di Bali. Teks tersebut mengisyaratkan ajaran-ajaran luhur Hindu yang sangan relevan dengan situasi moral zaman saat ini. Ajaran Itihasa ini dikenal tersirat dalam dua epos yakni Ramayana dan Mahabrata. Epos Mahabrata ini dipecah menjadi delapan belas parwa yang sangat dikenal dengan Asta Dasa Parwa. Dalam teks parwa ini sangat banyak tersirat pesan dan isyarat moral Hindu ketika menjalani hidup di dunia. Salah satunya tentu Santi Parwa. Dalam Santi Parwa termuat sebuah perdebatan sengit antara putra Pandu perihal ajaran etika kehidupan Hindu yang dikenal dengan Asrama Dharma. Di situ juga dijelaskan bahwa Hindu juga memberi legitimasi moral bagi umatnya untuk mencari harta dalam kehidupan di dunia berdasarkan pada prinsipprinsip Dharma.
\end{abstract}

\section{Kata Kunci:}

\section{ABSTRACT}

The texts of Itihasa are currently being loved by the people, especially Hindus in Bali. The text suggests the sublime teachings of Hinduism that are relevant to today's moral situation. Itihasa teachings are known to be implied in two epics namely Ramayana and Mahabrata. The epic of Mahabrata is broken down into eighteen parwa who are well known as Asta Dasa Parwa. In the text of this parwa is very much implied message and moral cues Hindu when living life in the world. One of them is Santi Parwa. In Santi Parwa contains a heated debate between the son of Pandu about the ethical teachings of Hindu life known as Dharma Dormitory. It also explains that Hinduism also gives moral legitimacy for its people to seek treasure in the life of the world based on the principles of Dharma.

\section{Keywords:}

\section{PENDAHULUAN}

Sumber utama ajaran Agama Hindu sebagaimana diyakini oleh para pemeluknya adalah pustaka Suci Veda. Dipandang dari sumbernya, Veda terbagi ke dalam dua kelompok besar, yaitu Veda Sruti dan Veda Smrti (Manavadharmasastra II. 10 dan sloka Sarasamuscaya, sloka 37).

Veda Sruti adalah ajaran-ajaran Agama Hindu yang bersumber dari wahyu Brahman yang disampaikan kepada para Maharsi India ribuan tahun yang lalu. Veda Sruti ini terdiri atas empat himpunan, yaitu Reg Veda, Sama Veda, Yayur Veda, dan Atharva Veda. Sedangkan Veda Smrti adalah himpunan ajaran-ajaran Hindu yang berisi tafsir wahyu Sang Hyang Widhi. Tafsir ini dibuat oleh para Maharsi, Acharya dan Avatar (Gorda, 2009: 28).

Agama Hindu dibangun di atas Tiga Kerangka Dasar yang terkait erat satu sama lain, sehingga membentuk kesatuan yang bulat, utuh, dan menyeluruh. Ketiga kerangka dasar tersebut adalah (1) Tattwa (filsafat),

Fungsi Tradisi Mebanten Tebasan 
yang berisi uraian filosofis tentang Panca Sradha, hubungan manusia dengan Sang Hyang Widhi, hubungan manusia dengan sesama dan hubungan manusia dengan alam sekitarnya, (2) Susila (etika), ajaran tentang perbuatan yang baik dan perbuatan yang tidak baik menurut norma-norma Agama Hindu (Sura, 2012: 5) dan (3) Upacara (ritual), yang merupakan rangkaian kegiatan umat Hindu dalam upaya berkomunikasi dengan Sang Hyang Widhi. Upacara diwujudkan dalam bentuk persembahan atau korban suci (Yajna) sebagai manifestasi konkrit dari agama (Upadesa, 2005: 14).

Ajaran Etika dalam Agama Hindu yang kian termarjinalisasi saai ini, atau hanya sebatas dipahami secara tekstual dan tidak menemukan kontekstualisasinya. Seperti ajaran Tri Kaya Parisudha, Catur Purusa Artha, Catur Asrama, Tri Hita Karana. Sebagai contoh saja ajaran Catur Asrama yang dimaknai sebagai tahapan-tahapan kehidupan dalam Agama Hindu yang akan dijalani manusia ketika telah terlahir ke dunia. Berawal dari masa Brahmacari, Grahasta, Wanaprastha dan bhiksuka. Dalam kenyataannya, pada saat ini tahapan kehidupan yang menjadi landasan moral Agama Hindu ini sudah menurun antara yang lebih didahulukan dan mana yang bisa diabaikan. Misalnya sekarang banyak orang yang hamil di luar nikah, padahal mereka sedang menjalani masa Brahmacari. Ada pula orang yang sudah menjalani kehidupan bhiksuka, namun masih terjebak dalam kebidupan grehasta yang bergelimpangan materi.

\section{PEMBAHASAN}

\section{A. Sinopsis Cerita Santi Parwa}

Santi Parwa adalah suatu naskah dalam bentuk cerita yang isinya tentang kemenangan Pandawa melawan Kurawa yang mengakibatkan Pandawa mengetahui kebenaran dari kelahiran Karna dan pendapat Yudisthira serta anak Pandawa tentang hidup
Grahasta, yang dapat digunakan sebagai tuntunan seseorang tentang kasta agar tidak melupakan kewajibannya tinggal di dunia.

Menurut Marsini menjelaskan bahwa ajaran Grahasta merupakan ajaran yang menuntun umat manusia untuk menjalani kehidupan berumah tangga (wawancara 10 Juli 2016). Dalam hal ini ada beberapa pokok ajaran Agama Hindu yang terdapat dalam Santi Parwa antara lain : ajaran Sraddha yaitu keyakinan yang mendasar dalam Agama Hindu (Titib, 2003: 168). Keyakinan ini merupakan prinsip dasar yang dipegang teguh oleh setiap umat Hindu. Adapun pokok-pokok keyakinan Agama Hindu terdiri dari lima bagian yang disebut dengan Panca Sraddha. Dengan adanya Panca Sraddha maka umat Hindu dapat menimbulkan rasa sujud bhakti kehadapan Sang Hyang Widhi sebab telah memiliki keyakinan akan adanya Beliau berdasarkan ajaran Agama Hindu. Adapun bagian-bagian dari Panca Sraddha sebagai berikut: 1) Percaya terhadap adanya Brahman atau Sang Hyang Widhi, 2) Percaya terhadap adanya Atman, 3) Percaya terhadap adanya Karmaphala, 4) Percaya terhadap adanya Punarbhawa, 5) Percaya terhadap adanya Moksa.

\section{B. Ajaran Catur Asrama}

Agama Hindu dikenal hirarki kehidupan etik yang bernama catur asrama. Catur asrama yang terdiri dari Brahmacari, Grahasta, Wanaprastha dan Sanyasin. Catur asrama ini adalah tingkatan kehidupan etik menurut Hindu (Cika, 2006: 19). Keempat masa ini dijalani sebagai jalan Dharma dan bhakti umat Hindu untuk mencapai tujuan akhir yakni Moksa. Keempat ajaran ini sebagai pedoman bagi umat Hindu dalam menjalankan aktivitasnya sehari-hari. Adapun bagian-bagian dari Catur Asrama sebagai berikut : 1) Ajaran Brahmacari, 2) Ajaran Grahasta, 3) Ajaran Wanaprasth, 4) Ajaran Sanyasin 


\section{Ajaran Etika Hindu dalam Cerita Santi Parwa}

\section{Makna Kerja Menurut Hindu}

Kerja pada umumnya selalu mengharapkan hasil yang sesuai dengan pengorbanan yang diberikan. Pengertian seperti ini merupakan anggapan yang berlaku bagi orang yang belum mengetahui empat jalan pengetahuan untuk bersatu dengan Brahman. Orang yang beranggapan demikian akan merasa bahwa apa yang ia kerjakan tidak dapat terlepas dari hasil yang diinginkan. Selanjutnya hasil disodorkan sebagai alat pemenuhan kebutuhan manusia.

Adapun makna kerja dalam Santi Parwa antara lain : 1) Jalan Mencari Kebenaran Sejati, yiatu Dasar filosofis dari keseluruhan ajaran moral Bhagawad Gita berpusat pada kehendak untuk bersatu dengan Brahman. Konsekuensi logis dari dasar pemikiran tersebut adalah bahwa manusia harus mengarahkan keseluruhan hidupnya bagi tercapainya tujuan tersebut. 2) Kerja Sebagai Niyatman, yaitu Niyatman berarti pekerjaan yang telah ditentukan artinya tiap-tiap orang dalam hidup ini mempunyai tugas pekerjaan yang telah di tentukan sesuai dengan bakat dan pilihannya sejak ia masih kecil. 3) Kerja Sebagai Yajna yaitu Yajna bararti pengabdian, persembahan dan berkaitan dengan Yatna Artha, yang berarti tujuan bakti, tujuan yang pengabdian, berbakti kepada Tuhan Yang Maha Esa. Dalam katagori Yajna dapat di bagi dalam; (a) berbakti kepada Brahman, (b) berbakti kepada Dewa, (c) berbakti kepada nenek moyang dan orang tua, (d) memberikan sedekah kepada yang miskin dan sengsara dan (e) memberi makan kepada binatang. Melakukan Yajna tersebut merupakan tugas manusia dalam hidup ini. Setiap pembaktian atau pemberian kepada mereka harus di lakukan dengan hati suci atau tulus iklas.

\section{Etika Kerja Hindu dalam Cerita Santi Parwa}

Pada dasarnya etika merupakan rasa cinta kasih, rasa kasih sayang, dimana seseorang yang menjalani dan melaksanakan etika itu karena ia mencintai dirinya sendiri dan menghargai orang lain. Etika menjadikan kehidupan masyarakat menjadi harmonis, karena saling menjunjung tinggi rasa saling menghargai antar sesama dan saling tolong menolong. Dengan etika akan membina masyarakat untuk menjadi anggota keluarga dan anggota masyarakat yang baik serta menjadi warga negara yang mulia.

\section{Ajaran Etika Kepemimpinan \\ 1. Kewajiban seorang Pemimpin}

Pemimpin adalah seseorang

yang memiliki kemampuan untuk menggerakkan orang lain untuk mencapai tujuan yang telah ditetapkan dan sebagai pengambil keputusan dalam menetapkan perencanaan operasional dan pengawasan (Wijaya, 2004: 36). Tanpa kepemimpinan dari seorang pemimpin yang cakap dan bijaksana suatu masyarakat, bangsa dan Negara akan mengalami keterpurukan dan kekacauan.

Seorang pemimpin diharapkan melaksanakan kepemimpinannya dengan sebaikbaiknya, sehingga akan tercapai tujuan yang diinginkan. Semua ini berlaku bagi semua pemimpin yang ada, baik ia sebagai pemimpin formal, informal dan besar maupun kecil. Hendaknya pemimpin yang kepemimpinan itu memiliki tujuan yang jelas, sebab pemimpin yang tidak memiliki tujuan yang jelas akan memberatkan masyarakat yang dipimpinnya.

\section{Melindungi Rakyat dengan Kebenaran}

Kepemimpinan merupakan proses mendorong dan membantu orang lain untuk bekerjasama secara antusias untuk mencapai tujuan yang telah ditetapkan (Gunadha, 2000:

Fungsi Tradisi Mebanten Tebasan 
4). Cerita Santi Parwa di dalamnya sangat banyak diajarkan dalam etika kepemimpinan. Menyimak sekarang ini, telah banyak terjadi penyalahgunaankekuasaan seorangpemimpin, tidak hanya di pemerintahan, melainkan juga di instansi swasta. Maraknya tindak pidana kerupsi yang sampai menyeret beberapa pemimpin di daerah membuktikan bahwa sedang ada persoalan etika kepemimpinan. Pemimpin tidak begitu memahami apa itu arti kepemimpinan dan bagaimana kewajiban pemimpin sesuai yang diamanatkan ajaran agama khususnya Hindu.

\section{SIMPULAN}

1. Santi Parwa adalah suatu naskah dalam bentuk cerita yang isinya tentang kemenangan Pandawa melawan Kurawa yang mengakibatkan Pandawa mengetahui kebenaran dari kelahiran Karna dan pendapat Yudisthira serta anak Pandawa tentang hidup Grahasta, yang dapat digunakan sebagai tuntunan seseorang tentang kasta agar tidak melupakan kewajibannya tinggal di dunia. Dalam cerita Santi Parwa berisi tentang ajaran Panca Sradha yang meliputi percaya terhadap adanya Brahman atau Sang Hyang Widhi, percaya terhadap adanya Atman, percaya terhadap adanya Karmaphala, percaya terhadap adanya Punarbhawa dan percaya terhadap adanya Moksa serta Catur Asrama yaitu Brahmacari, Grahasta, Wanaprastha dan Sanyasin.

2. Cerita Santi Parwa menyiratkan dua ajaran Etika Hindu yakni etika kerja dan etika kepemimpinan. Etika kerja menyangkut tentang pedomanpedoman kerja yang diterapkan dalam mencapai kebahagiaan sejati. Dalam Hindu, sebagaimana yang tertuang pasa cerita Santi Parwa, kerja merupakan kewajiban yang dijalankan oleh manusia di dunia. Dengan cara bekerja umat manusia mampu mencari kebahagiaan sejati. Jalan ini dalam Hindu dikenal sebagai Karmayoga. Tujuan kerja adalah Artha atau hasil dari kerjaan. Hasil ini didapat melalui Kama. Namun Artha dicapai dengan prinsip-prinsip Dharma untuk kebahagiaan sejati yakni Moksa. Etika kerja Hindu yang tertuang dalam cerita Santi Parwa meliputi tiga pedoman tersebut dengan tujuan kebahagiaan sejati. Selain itu, dalam cerita Santi Parwa mengajarkan prinsip etika sebagai seorang pemimpin. Pemimpin memiliki beberapa kewajiban yakni mensejahterakan rakyat, menjunjung kebenaran dan keadilan dan menegakkan hukum dengan baik. Salah satu yang menarik adalah seorang pemimpin berkewajiban bersikap welas asih kepada para Brahmana, karena Brahmana wakil dari Dewa yang ada di bumi.

\section{DAFTAR PUSTAKA}

Ali, Sayuti. 2002. Metode Penelitian Agama. Jakarta: PT Raja Grafindo

Arikunto, Suharsimi, 2002. Prosedur Penelitian Suatu Pendekatan Praktis. Jakarta: PT. Rineka Cipta

Kattsoff, O Lois, 2004. Pengantar Filsafat. Yogyakarta: Tiara Wacana

Krsnan, Radha. 2009. Bhagawad Gita. Surabaya: Paramita

Koentjaraningrat. 2013. Sejarah Teori Antropologi I. Jakarta: Universitas Indonesia Press

Majalah Sarad. 2004. Pilih-pilih Kerja Orang Bali. Denpasar: Majalah Gumi Bali

Maswinara, I Wayan. 2010. Sistem Filsafat Hindu. Surabaya: Paramita

Mestika, Zed. 2004. Metodologi Penelitian Kepustakaan. Jakarta: Yayasan Obor Indonesia 
Moleong, J Lexy, 2009. Metodologi Penelitian Kualitatif. Bandung: PT. Remaja Rosdakarya

Pendit, Nyoman S. 2008. Mahabharata. Jakarta: Bhatara Karya Aksara

Pudja, Gede. 1999. Bhagawadgita (Panca Weda). Sirabaya : Paramita.

Punyatma, Oka. 1994. Cilakrama. Denpasar : Upada sastra.

Ritzer, George dan Douglas J. Goodman. 2011. Teori Sosiologi Modern. Jakarta : Kencana.

Ridwan,. 2004. Metode Dan teknik Penyusunan Tesis. Alvabeta : Bandung.

Syuropati, Soebachman. 2012. 7 Teori Sastra Kontemporer \& 17 Tokohnya. Yogyakarta : IN AzNA Books.

Sriasih, Sang Ayu Putra, 2012. Kearifan Lokal dan pendidikan Karakter. Prosiding Konfrensi Internasional Budaya Daerah ke-2 (KIBD-II) Denpasar : Pustaka Lasaran bekerja sama dengan IKIP PGRI BALI dan IKADBUDI. 